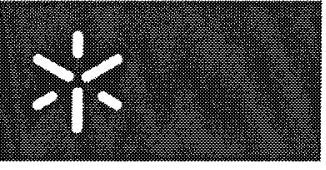

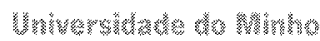

$[\mathrm{Cl}-24]$

Pais, J.C., Pereira, P.A.A., Sousa, J.B., Capitão, S.

"Evaluation of the load associated cracking in flexible pavements"

Sixth International Conference on the Bearing Capacity of Roads, Railways and Airfields, Lisboa, Portugal, 2002, p. 585-594 


\section{Table of Contents}

Introduction

A. Gomes Correia \& Ivar Horvli

Preface

XIII

Fernando E.F. Branco

Organization

Bearing capacity policies, concepts, costs and condition surveys

A New Deflection Measuring System for Pavements in Spanish Airports Based on Laser Technology

P.P. Carrasco, L. Martín

Monitoring Pavement Response during Spring Thaw Using Fiber-Optic Sensors

G. Doré, G. Duplain

Evolution of French Airport Bearing Capacity Assessment

J.-P. Guillon, J.-C. Deffieux

Inconsistencies in Rating the Effect of Aircraft Load and Reporting the Bearing

Capacity of Pavements

A. Loizos, C. Abacoumkin, G. Charonitis

Evaluation of Rigid Pavement Condition Using Falling Weight Deflectometer

M.M. Pradhan

Non-Contact Deflection Measurement at High Speed

S. Rasmussen, J.A. Krarup, G. Hildebrand

Application of Image Analysis to the Identification and Rating of Road Surface Distress

C. Rasse, V. Leemans, M.-F. Destain, J.-C. Verbrugge

ROADEX - Benchmarking Low Traffic Volume Road Condition Management in EU Northern Periphery Area

T. Saarenketo, S. Bell, G. Berntsen, S. Sundberg, E. Vuontisjärvi

Pavement Condition Survey at a Motorway Section in Croatia: Maintenance and Rehabilitation Activities 


\section{Analysis and modeling}

A Simple Damage Approach to Modelling Fatigue in Bituminous Materials

Y.K. Choi, A.C. Collop, N.H. Thom

Ultra-Thin Whitetoppings: A 2-D Finite Element Parametric Study

W. De Corte, D. De Leersnyder, E. De Winne

A Mechanical Model for the Prediction of the Tire/Road Friction

M.-T. Do, F. Hammoum

Material Models for Reinforced Unbound Aggregate

G. Eiksund, I. Hoff, G. Svanø, A. Watn, E.V. Cuelho, S.P. Perkins,

B.R. Cristopher, C.W. Schwartz

3-D FE Analysis of Test Road Structures - Comparison with Measurements

S. Erlingsson

Dynamic Analysis of FWD Data for Pavement Evaluation

E. Fernando, W. Liu

Limiting Equilibrium Methods in Bearing Capacity Analysis of

Flexible Pavements Reinforced with Geosynthetics

T.C. Hopkins, M.E. Slepak, L. Sun

Mechanistic Model for Road Design in Sweden

A. Huvstig

Stress Paths in Flexible Pavements Subjected to Severe Climatic Conditions

J.-M. Konrad, S. Zhou

Backcalculation of Thin Air - A Way to Cope with Slipping and

Sliding Layer Interfaces

C.A. Lenngren

Initial Rutting on Reconstructed Roads and How It Relates to FWD Testing II

C.A. Lenngren, R. Fredriksson

Reinforcement of Flexible Pavements - Design of Finite Element Models

S. Neßlauer

Prediction of Flexible Pavement Response Using Non-Linear Stress-Dependent

Material Models

S.-W. Park, R.L. Lytton 
Flexible Airport Pavement Evaluation for New Generation Aircraft using

ILLI-PAVE-Based Concepts

M. Thompson, F. Gomez-Ramirez

Evaluating of Overlay on Concrete Slab in Airport with 3D FEM

S. Wu, R. Yin

\section{Design and environmental effects}

Development of Pavement Temperature Prediction Model for Asphalt Concrete Pavements

M.A.H. Abo-Hashema, F.M. Bayomy

Effect of the Variability of Seasonal Moduli Adjustment Factors on the Mechanistic-Empirical Overlay Design

F.M. Bayomy, M.A.H. Abo-Hashema

Critical Stresses for Thickness Design of Rigid Pavement Slabs Subjected to Multiple-Axle Heavy Aircraft Gear Loads

D.R. Brill, E.H. Guo, L. Ricalde

Temperature Variation and Displacement Behavior of Model Asphalt Pavements During Repeated Plate-Loading Tests

E. Hirotsu, N. Yoshida, Masaru Nishi, H. Kanki

Airfield Pavement Structural Analyses and Design in Sweden

C.A. Lenngren, H. Carlsson

Impact of Heavy Vehicles on Pavement Responses

P.E. Sebaaly, R. Siddhartan, D.L. Huft, D. Bush

Pavement Detriment Due to Runway Roughness

M.J.A. Stet, H.P.M. Thewessen

New Experiences in Loading of Flexible Pavements

V. Vodopivec, V. Oštir, B. Lipoglavšek

A New Approach to Pavement Design in Sweden: New Swedish Road Design Manual 
Pavement Design for the 3rd Runway at Stockholm-Arlanda Airport, Sweden

H. Wolgé, L. Näslund

\section{Construction, maintenance and rehabilitation}

Characterisation of Dense-Graded Asphalt Cold Mixtures for Pavement

Rehabilitation

F.A. Batista, M.L. Antunes

Variation in Calculated Pavement Performance Due to Variation in Input Data

P. Ekdahl

Could Adherence of a Road Surface be used to Identify the Areas

where Maintenance is Needed?

M. Gothié

Bearing Capacity of Flexible Road Structures Reinforced with Steel Fabrics

K. Gustafson, S. Said, L.G. Wiman

Implementation of Nondestructive Structural Evaluation for Airport

Asphalt Pavements

Y. Hachiya, Y. Tsubokawa, O. Takahashi

Effects of New and Conventional Deicing Chemicals on Airfield Asphalt

Concrete Pavement

Y. Hassan, A.O. Abd El Halim, A. El-Desouky, A. Mostafa, M. Farha

Long-Term Monitoring of an Open Graded Drainage Layer Design for Airfields at the Prince George Airport, British Columbia, Canada

M.J. Hovan, R. Resaul

Rockfill pavements on Soft Subsoil-Construction and Compaction

B. Johansson

A Probabilistic Method for Estimating Pavement Performance Using Falling Weight Deflectometer Data

O. Melchor-Lucero, I. Abdallah, S. Nazarian, C. Ferregut

Pavement Edge Drain Barriers in the Rehabilitation of Existing Roads

(Experiments and Fields Results)

J.L. Paute

Evaluation of Pavement Structure Reinforced with Steel Fabrics

S.F. Said, H. Zarghampour, S. Johansson, H. Hakim, H. Carlsson

Network Level Analysis of Pavement Maintenance in Norway

E.K. Sund, T. Haugødegård

QUASAR Structural Analysis of Asphalt Pavements

C.A.P.M. van Gurp, A.J. van Leest 


\section{Reflective cracking}

Laboratory Measurement of Crack Propagation in High Stiffness Asphalt Mixtures

A.C. Collop, N.H. Thom, A.J. Sewell

Estimation of Relative Performance of Overlaid Asphalt Concretes against

Reflection Cracking due to Shear and Bending Fracture Mode

K.W. Kim, S.J. Lee, Y.S. Doh, S.K. Rhee, T.S. Park

Pavement Deterioration - Crack Initiation and Crack Propagation Models

W. Lars-Göran

The Influence of Cracking on the Structural Properties of Asphalt Mixes

F.O. Martínez, S.M. Angelone

Crack Element in the Non-Linear f.e.m. Program PA.R.M.A. for the Design of Reinforced Concrete Pavements

A. Montepara, F. Giuliani

Evaluation of the Load Associated Cracking in Flexible Pavements

J.C. Pais, P.P.A. Pereira, J.M.B. Sousa, S. Capitão

\section{Field Tests for layer moduli evaluation}

Efficient Backcalculation Algorithmof Time Domain for Large-Scale Pavement

Systems using Ritz Vectors

Q. Dong, Y. Hachiya, O. Takahashi, Y. Tsubokawa, K. Matsui

Method of Estimation of Bearing Capacity of Multi-Layer Pavements with Application of Quasi-Static Tests

M. Graczyk, T. Mechowski, J. Sudyka, M. Chomicki, J. Rafa

Evaluation of the Influence of Asphalt Concrete Pavement Discontinuities on

Falling Weight Dflectometer Measurements

S. Grenier, J.-M. Konrad

In Situ Assessment of Stiffness of a Road Sand Embankment

W. Haegeman

Repeatability, Reproducibility and Accuracy of GPR Measurements

V. Hopman, E. Beuving

Backcalculation of Pavement Layer Moduli without Using D0-Deflection

J.W. Maina, T. Inoue, A. Kasahara, K. Matsui

Falling Weight Deflectometer Configuration Standards for Airfield Testing 
Use of Backcalculated Falling Weight Deflectometer Modulus for Detecting

Foundation Problems Caused by Rubblization of Concrete Pavements

Y. Mehta, B. Birgisson, B. Choubane

Bearing Capacity of a Flexible Pavement During the Construction Phase

J.M.C. Neves, A. Gomes Correia

Elastic Analysis of Thin Pavements and Subgrade Soil Based on Field and

Laboratory Tests

685

W.P. Núñez, J.A. Ceratti, W.Y.Y. Gehling, J.A. Oliveira

Validation of FWD Measurements in Connection with Outsourcing Contract

J.P. Pedersen, O. Noer, O. Olsen, D. Marquat, P. Offrell

Multichannel Analysis of Seismic Waves for Layer Moduli Evaluation of Pavements

705

N. Ryden, P. Ulriksen, U. Ekdahl, C.B. Park, R.D. Miller

Pavement Structural Evaluation: Production Level FWD Back-Analysis

Using the Full Time History

G. Salt, D. Stevens, R. McLeod

Using Seismic Investigation to Test the Interface between Two Pavement Layers

J.M. Simonin

Experimental and Theoretical Comparison of Dymanic Plate Testing Methods

N.H. Thom, P.R. Fleming

In Situ Evaluation of Seasonal Variability of Subgrade Modulus Using

DCP and FWD Tests

W. Uddin

Standard and Recommended Practices for FWD based Evaluation and Reporting Strength of Airfield Pavement

J.P. Verbeek, M.J.A. Stet

A Rapid Approach to Interpretation of SASW Results

H. Wu, S. Wang, I. Abdallah, S. Nazarian

An Initiative Toward Mechanistic Construction Quality Control: Using

Seismic Methods

D. Yuan, S. Nazarian

Author Index 


\title{
Evaluation of the Load Associated Cracking in Flexible Pavements
}

\author{
J.C. Pais \& P.P.A. Pereira \\ University of Minho, Department of Civil Engineering, 4800-058 Guimarães, Portugal
}

J.M.B. Sousa

Consulpav, Taguspark, Edificio Tecnologia I, n.26, 2780 Oeiras, Portugal

S. Capitão

Department of Civil Engineering of the Superior Institute of Coimbra, Quinta da Nora, Apartado 10057, 3031-601 Coimbra, Portugal

\begin{abstract}
The overlay of a cracked pavement is subject to reflective cracking due to the existing crack potential. In a cracked pavement, this cracking potential, due to traffic loads and temperature gradient, can be evaluated by means of crack activity. Traffic loads cause vertical and horizontal activity between the two edges of the cracks. These activities are caused by rocking of blocks between the cracks as well as by the shape of the deflection basin, combined with the size of the blocks. The temperature gradient causes horizontal activity between the two edges of the cracks. The main goal of this work is the evaluation of the crack activity before and after an overlay and its evolution during pavement life. This work was done monitoring 50 cracks in two trial section of an in service pavement. Models for crack activity before and after overlay were developed, based on finite elements, and applied in this case.
\end{abstract}

KEYWORDS: Crack activity before overlay, crack activity after overlay, finite elements, crack activity meter, falling weight deflectometer

\section{INTRODUCTION}

Overlays are the most commonly used method for pavement rehabilitation. However, they often do not perform as desired due to existing cracks, which can quickly propagate through the new overlay. This type of cracking is commonly referred to as reflective cracking. It is a result of differential vertical and horizontal movements above the old crack tip. Such movements, also called crack activity, are caused by thermal stresses, traffic loads, or by a combination of these two mechanisms. Stress concentrations are induced in the new overlay by virtue of crack activity. Thus the existing crack pattern observed in the original pavement oftentimes quickly propagates up through the new overlay.

Pavement cracks that exist before overlay exhibit varying degrees of crack activity as a function of pavement properties, mainly pavement layer thickness and stiffness for an applied load. After overlay, the existing cracks exhibit crack activity as a function of the crack activity before overlay, and of the overlay properties (thickness and stiffness). 
The crack activity before overlay plays an important role in the mechanistic characterization of existing pavements, but when conducting an overlay design the crack activity after overlay is required to evaluate the pavement's resistance to reflective cracking in bituminous (asphalt) mixes.

\section{CRACK ACTIVITY}

Crack edges are subject to relative movements mainly as a function of wheel load position and pavement properties. These movements can be represented by a combination of a bending, a shearing and a tearing. The tearing only appear in special situations mainly when the applied load is close to the end of the crack. So, only the first two opening modes should be considered in flexible pavement evaluation.

Due to traffic loads, the movements occur in pavement cracks depending on the position of a wheel load. The first mode is usually observed when a wheel load passes over a transverse or longitudinal crack. The second mode is observed when a wheel load approaches a transverse crack or when the load passes by the edge of a longitudinal crack. Figure 1 represents these modes, as proposed by Pais (1999).

From this analysis, it can be concluded that the most frequently observed modes of cracking in flexible pavements are Modes 1 and 2, representing the horizontal and vertical movements between the two edges of a crack. These movements are commonly called "crack activity" (Rust, 1987), and they can be evaluated directly in an existing pavement using any type of high precision measurement device, usually with a crack activity meter (CAM) or two sensors of a falling weight deflectometer (FWD).

The use of a FWD only allows the measurement of one direction crack activity while with the CAM, which is composed by two transducers, the vertical and horizontal crack movements can be evaluated. When the FWD is used only the vertical movements are measured.

The measurement with the CAM requires the use of a track, which passes very slowly near the CAM that is glued to the pavement (between the two edges of the crack). This is a slow process and very dangerous for the CAM integrity, as observed in Figure 2.

In the case of a FWD, the load plate is placed close to the crack and two geophones are manually placed between the two edges of the crack. This procedure presented in Figure 3, used to measure the crack activity after overlay, is very quick and any danger for the used material occurs.

Longitudinal cracks
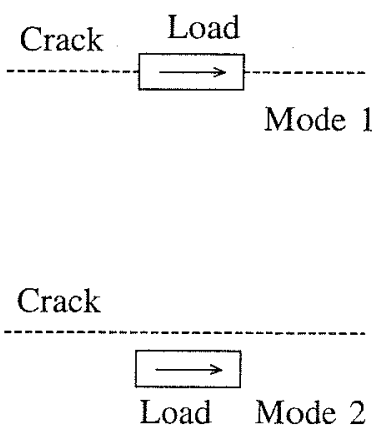

Transverse cracks
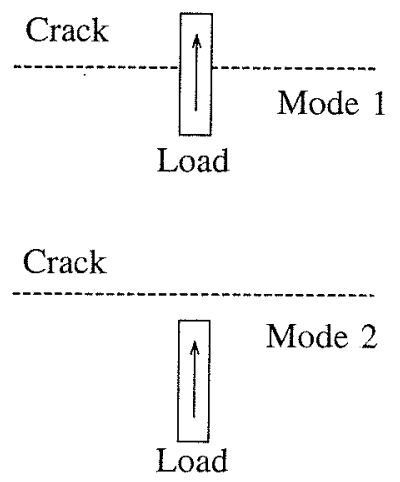

Figure 1. Crack activity modes as a function of location of load (Pais, 1999). 


\section{CRACK ACTIVITY BEFORE PAVEMENT OVERLAY}

The evaluation of crack activity before overlay was made on 50 cracks of two cross sections (CS1 and CS2), each of which were $100 \mathrm{~m}$ long, in the flexible pavements of a Portuguese road. The measurements were made in four different times during two years (May 98, Sep 98, Mar 99 and Jun 99).

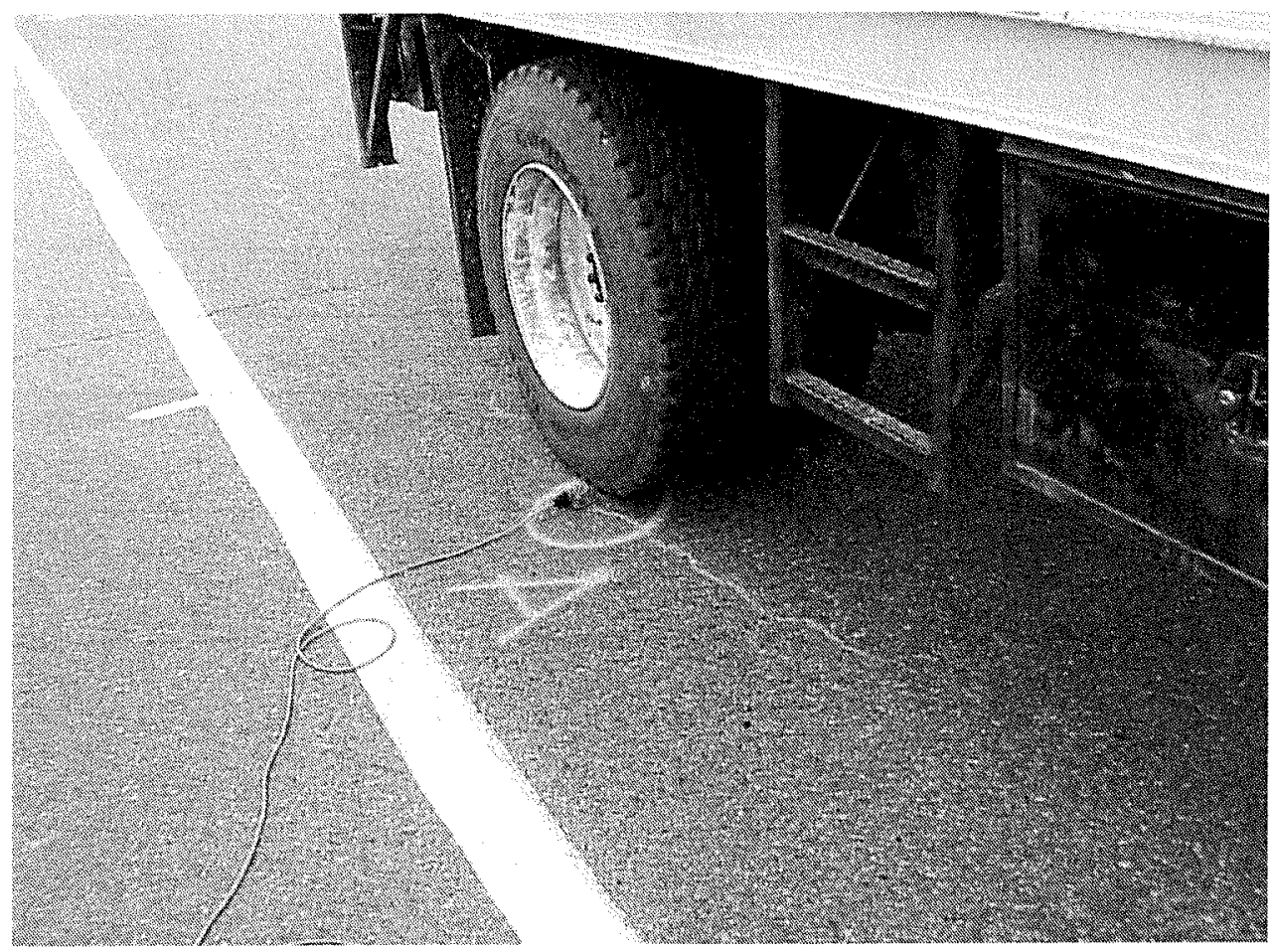

Figure 2. Measurement of the crack activity before overlay with the CAM device and truck.

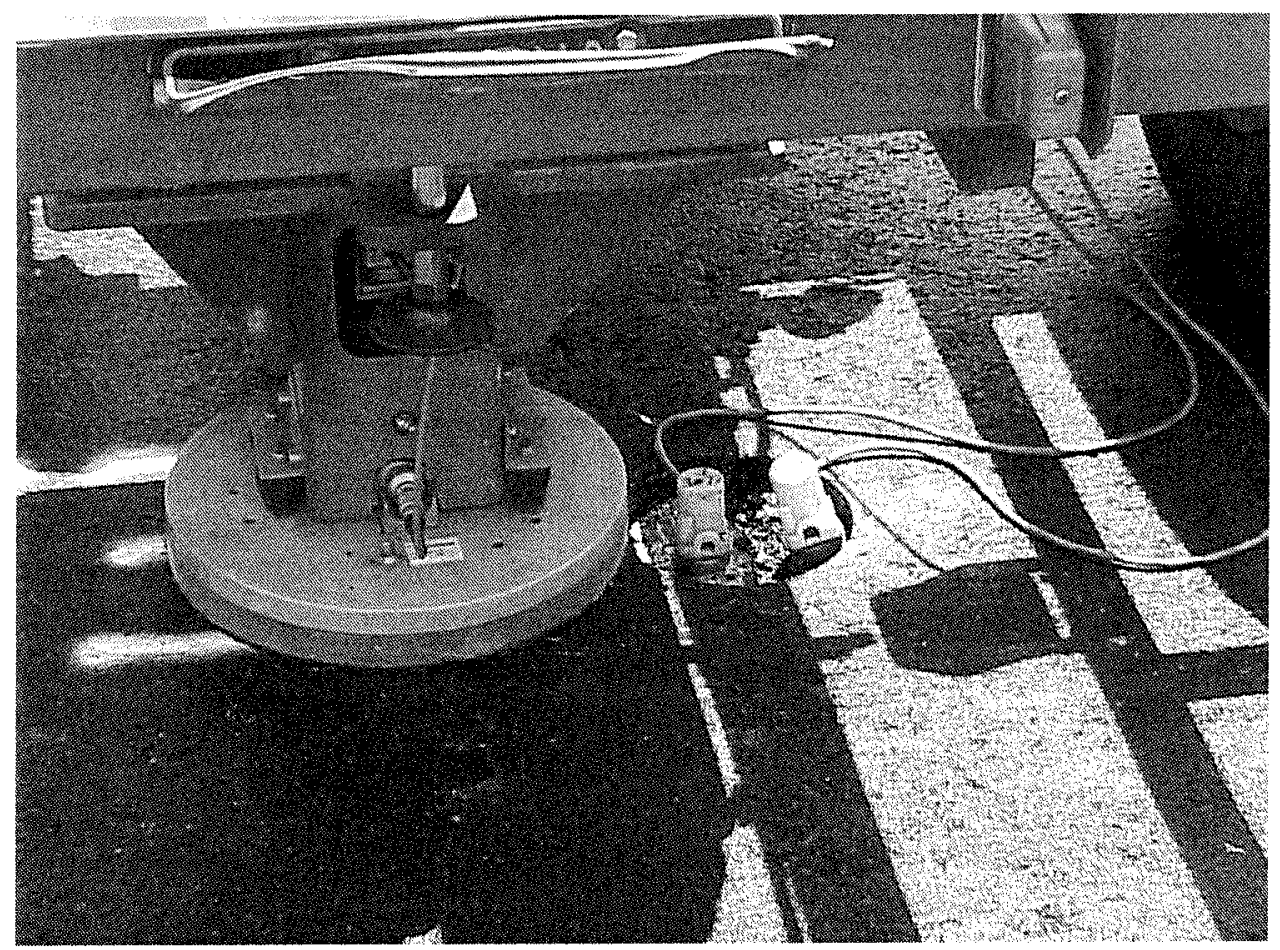

Figure 3. Measurement of the crack activity after overlay with the FWD. 
Table 1. Characterization of cross-sections.

\begin{tabular}{|c|c|c|c|c|}
\hline \multirow{2}{*}{$\begin{array}{l}\text { Cross-section } \\
\text { (CS) }\end{array}$} & \multirow[t]{2}{*}{ Time } & \multicolumn{3}{|l|}{ Stiffness (MPa) } \\
\hline & & Bituminous $\left(20^{\circ} \mathrm{C}\right)$ & Granular & Subgrade \\
\hline 1 & May 98 & 5400 & 500 & 80 \\
\hline 2 & & 3100 & 400 & 70 \\
\hline 1 & Sep 98 & 3100 & 375 & 60 \\
\hline 2 & & 2250 & 190 & 75 \\
\hline 1 & Mar 99 & 2800 & 310 & 60 \\
\hline 2 & & 2100 & 150 & 65 \\
\hline 1 & Jun 99 & 2500 & 350 & 70 \\
\hline \multirow[t]{3}{*}{2 . } & & 1500 & 210 & 70 \\
\hline & & \multicolumn{3}{|l|}{ Thickness (m) } \\
\hline & & Bituminous & \multicolumn{2}{|l|}{ Granular } \\
\hline \multirow{2}{*}{\multicolumn{2}{|c|}{$\begin{array}{l}1 \\
2\end{array}$}} & 0.20 & \multicolumn{2}{|l|}{0.60} \\
\hline & & 0.20 & \multicolumn{2}{|l|}{0.64} \\
\hline
\end{tabular}

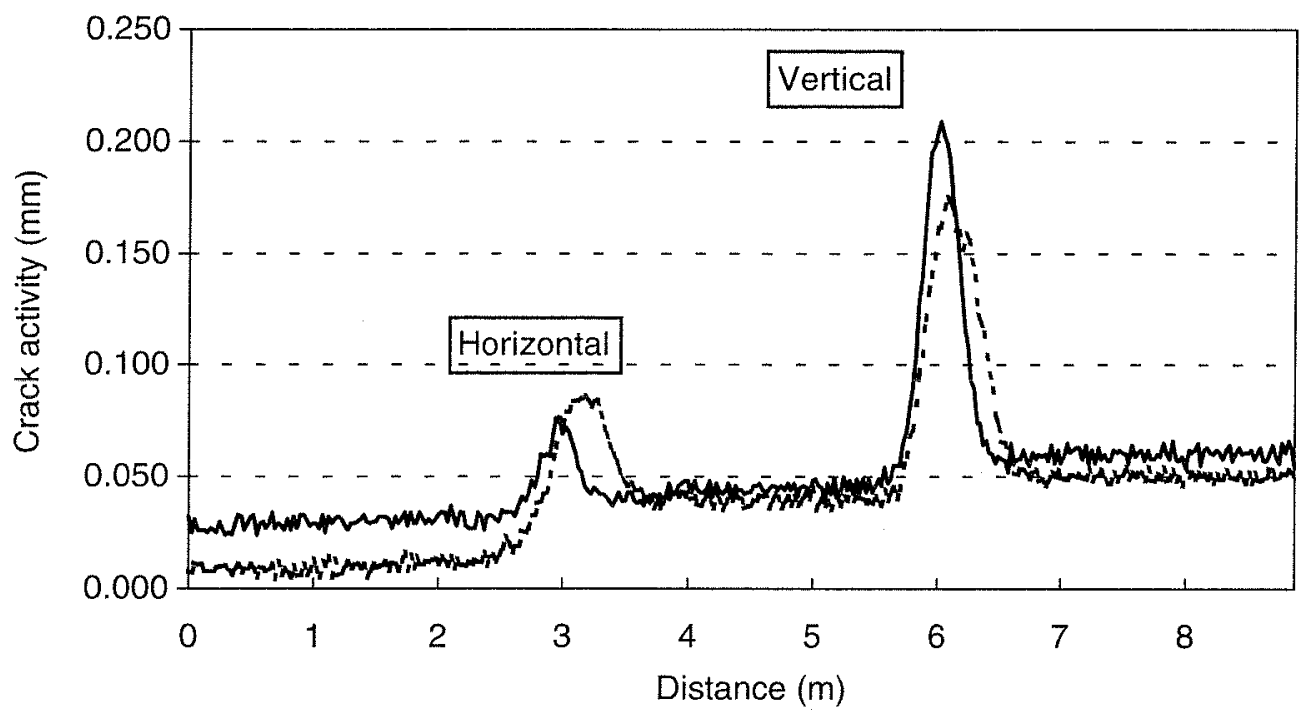

Figure 4. Typical crack activity influence line for longitudinal cracks measured with the CAM.

In all two cross-sections, layer thickness was measured by coring and layer stiffness was measured by back-calculation from FWD data.

The results are presented in Table 1, where all asphalt-bound layers were combined into a single layer called "bituminous" and all granular layers, excluding the subgrade, were combined as a single layer called "granular". This combining of adjacent layers was carried out in order to define representative pavement structures having only three effective layers, allowing for the characterization of pavements using five parameters (two thicknesses and three stiffnesses).

\subsection{Measured Crack Activity in Pavement}

Typical crack activity influence line for a longitudinal crack is shown in Figure 4. Figure 5 shows typical crack activity influence line for a transverse crack. Positive values for horizontal crack 


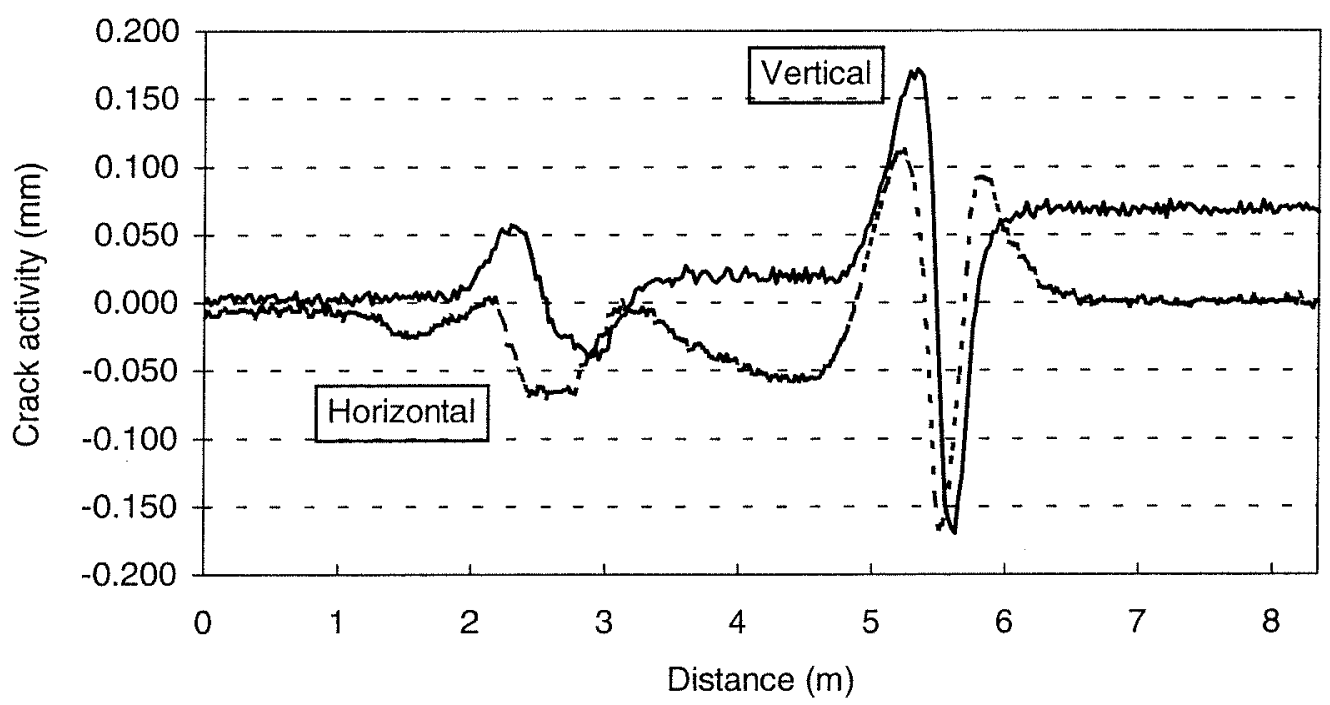

Figure 5. Typical crack activity influence line for transverse cracks measured with the CAM.

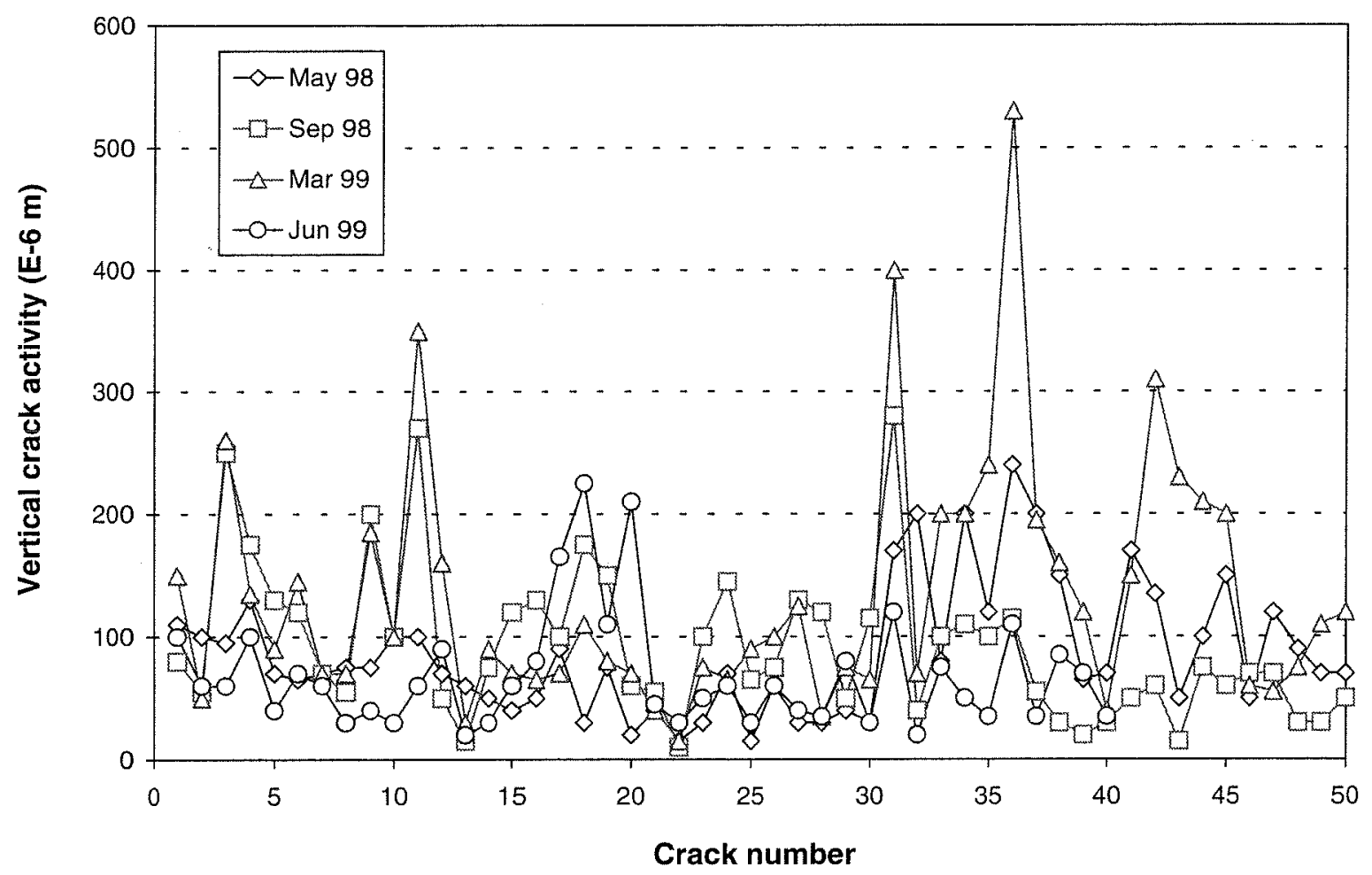

Figure 6. Vertical crack activity before overlay in all cracks.

movements indicate opening or widening of a crack, while negative values represent closing or narrowing of a crack. In these figures, the distance represents the load track movement.

From crack activity influence line, both for longitudinal and transverse cracks, the crack activity is obtained, which represent the maximum amplitude of crack activity. For transverse cracks, only the ascendent part of the influence line was considered to define the crack activity.

In Figure 6 the vertical crack activity before overlay is presented for all 50 cracks. The first 30 cracks correspond to the CS1 and the other 20 cracks correspond to the CS2. Longitudinal cracks are the crack number: $3,5,6,9,11,12,16,18,20,22,24,27,34,36,47$ and 48. Figure 7 shows the horizontal crack activity before overlay. 


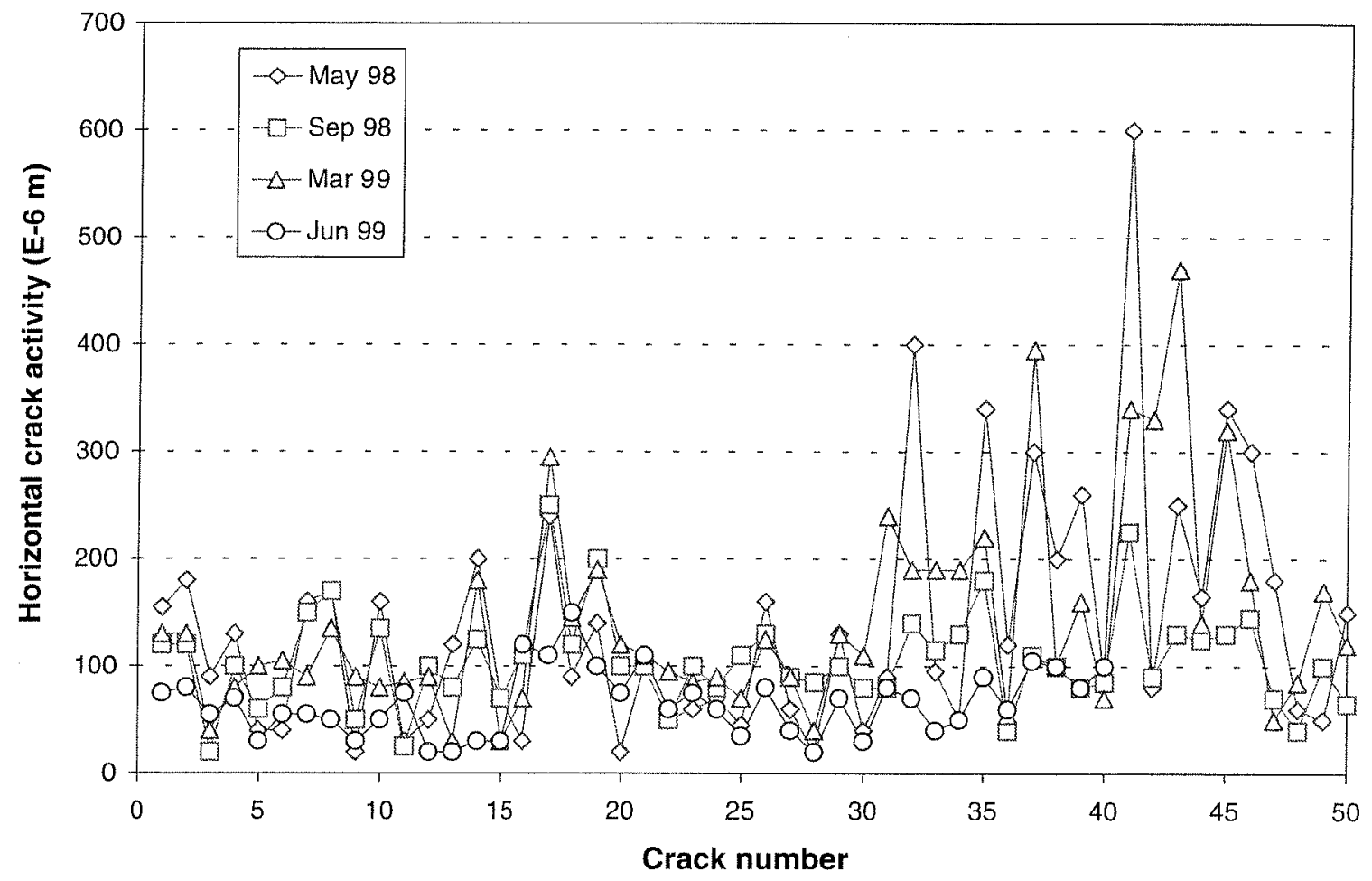

Figure 7. Horizontal crack activity before overlay in all cracks.

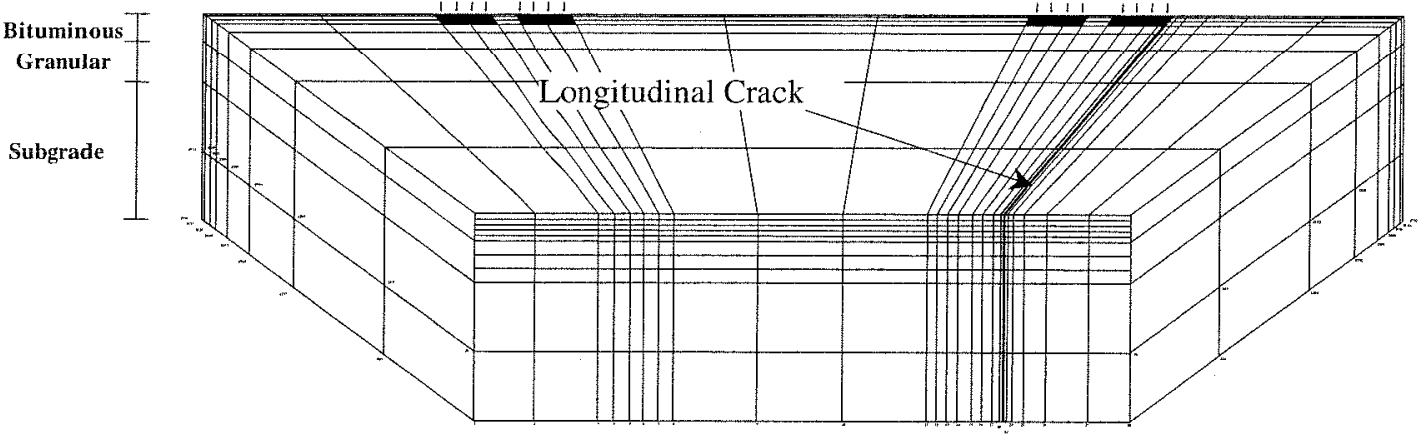

Figure 8. 3D finite element mesh used to calculate the crack activity before overlay.

No expressive differences were found between the crack activity measured on longitudinal and transverse cracks. So, the crack activity was jointed in only one group that include both longitudinal and transverse cracks.

The analysis of the results of vertical and horizontal crack activity before overlay shows that some differences can be found during the winter and summer months. These differences were more effective on CS2, during the winter the cracks showed the highest crack activity.

\subsection{Estimated Crack Activity}

Finite elements, in a 3D representation, as presented in Figure 8, were used to develop a model to estimate the crack activity before overlay. The pavement was modeled as a 3 layers pavement, with a bituminous cracked layer, a granular layer and a subgrade layer. A longitudinal crack is 


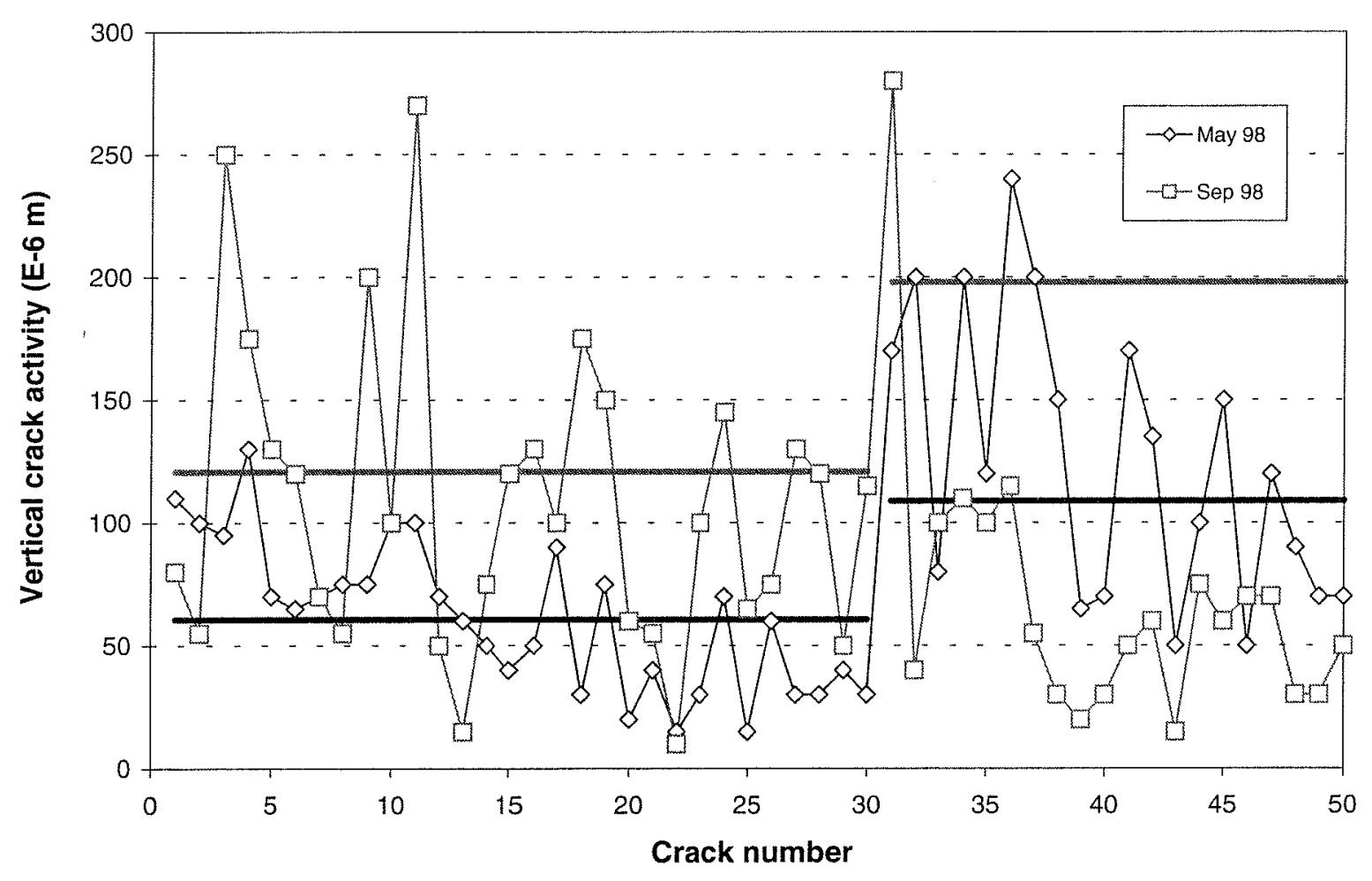

Figure 9. Comparison between measured and predicted vertical crack activity before overlay.

also represented in a model with $4.70 \mathrm{~m} * 2.4 \mathrm{~m}$ (due to symmetrical pavement configuration) * pavement thickness. If the pavement has more than 3 layers, a usual situation in flexible pavements, layers of identical materials must be included in one layer.

Using the 3D finite element model, the vertical crack activity before overlay was calculated to fit in a statistical model and the Equation 1 was obtained.

$$
\begin{aligned}
A c t= & 11.773 \log (\text { Tbet })-21.388 \log (\text { Tgra })-52.893 \log (\text { Mbet }) \\
& -94.619 \log (\text { Mgra })-16.418 \log (\text { Msub })+1181.66 \quad R^{2}=0.95
\end{aligned}
$$

where Act $=$ vertical crack activity before overlay $(10-6 \mathrm{~m})$, Thet $=$ bituminous cracked layer thickness $(\mathrm{m})$, Tgra $=$ granular layer thickness $(\mathrm{m})$, Mbet $=$ bituminous cracked layer modulus $(\mathrm{MPa}), \mathrm{Mgra}=$ granular layer modulus $(\mathrm{MPa})$ and $\mathrm{Msub}=\operatorname{subgrade}$ modulus $(\mathrm{MPa})$.

It has been demonstrated by Pais et al. (2000) that the most important component of the crack activity is the vertical displacement. This is so because after an overlay the horizontal displacements are reduced to extremely small values. Because the crack activity before overlay was developed only for the vertical crack activity.

The application of the model developed to predict the vertical crack activity before overlay was made to the crack activity measurements in Mar 99 and Sep 99 for both cross-sections. The results are presented in Figure 9 where the horizontal lines represented the estimated values given by the statistical model. It can be concluded that on the average the model represents well the in situ measurements.

\section{CRACK ACTIVITY AFTER PAVEMENT OVERLAY}

Overlay design methods that takes reflective cracking into account must recognize that crack displacements are responsible for the propagation of existing cracks through the overlay, in other words the crack activity after overlay. 


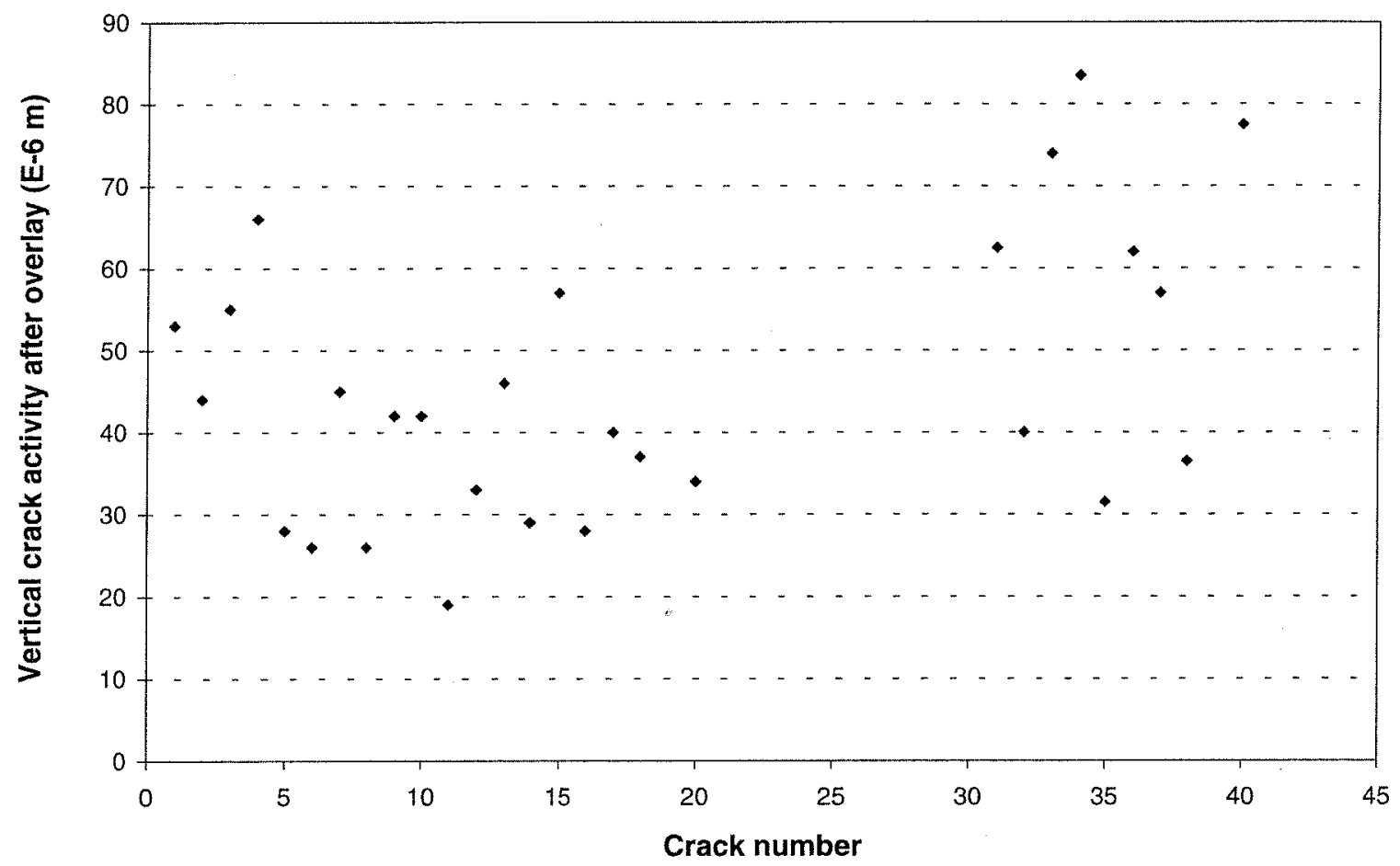

Figure 10. Vertical crack activity after overlay.

Crack activity measured in the pavement before the overlay is different from crack activity after overlay, since this will depend on the overlay thickness material stiffness. Crack activity after overlay can be estimated using a finite element analysis knowing the existing pavement and overlay material properties.

The crack activity after overlay measured in the pavement requires access to the top of the cracked layer. This can be accomplished in two ways. In the first way a piece of wood with the overlay thickness is placed over the crack and the bituminous mixture is placed around it just prior to overlay compaction. After the pavement cools down the wood can be taken off providing access to the existing crack. In the other way a double aluminium foil sheet is to be placed on the crack and the overlay is placed. After the pavement cools down the overlay is cored until the existing pavement at a location given by accurate measurements. This situation can be found in Figure 3.

\subsection{Measured Crack Activity in Pavement}

For the measurement of the crack activity after overlay the FWD device was used which give only the amplitude of the activity after overlay. No influence line was obtained for this type of measurements. Once the FWD was used to measure the crack activity after overlay only the crack activity in one direction was measured. As demonstrated by Pais et al. (2000), the vertical crack activity after overlay should be measured instead of the horizontal. The results of the crack activity after overlay are presented in Figure 10.

The crack after overlay was measured in Aug 2000 on CS2 (cracks 30-40) and May 2001 on CS1 (cracks 1-20). The cracks 41-50 were eliminated because the pavements fails before overlay and it was rebuild. The crack activity after overlay on cracks 21-30 was not yet measured. The overlay thickness on existing cracks range from 7.5 to $13 \mathrm{~cm}$ as presented in Table 2. 
Table 2. Overlay thickness for each crack.

\begin{tabular}{llllllll}
\hline Crack & $\begin{array}{l}\text { Overlay } \\
\text { thickness } \\
(\mathrm{cm})\end{array}$ & Crack & $\begin{array}{l}\text { Overlay } \\
\text { thickness } \\
(\mathrm{cm})\end{array}$ & Crack & $\begin{array}{l}\text { Overlay } \\
\text { thickness } \\
(\mathrm{cm})\end{array}$ & Crack & $\begin{array}{l}\text { Overlay } \\
\text { thickness } \\
(\mathrm{cm})\end{array}$ \\
\hline 1 & 8 & 8 & 11 & 15 & 13 & 33 & 12.5 \\
2 & 7 & 9 & 11 & 16 & 13 & 34 & 13 \\
3 & 7 & 10 & 11 & 17 & 13 & 35 & 13 \\
4 & 10 & 11 & 11 & 18 & 12 & 36 & 11 \\
5 & 10 & 12 & 13 & 20 & 12 & 37 & 11 \\
6 & 11 & 13 & 11 & 31 & 12.5 & 38 & 10.5 \\
7 & 11 & 14 & 13 & 32 & 12.5 & 40 & 11.5 \\
\hline
\end{tabular}

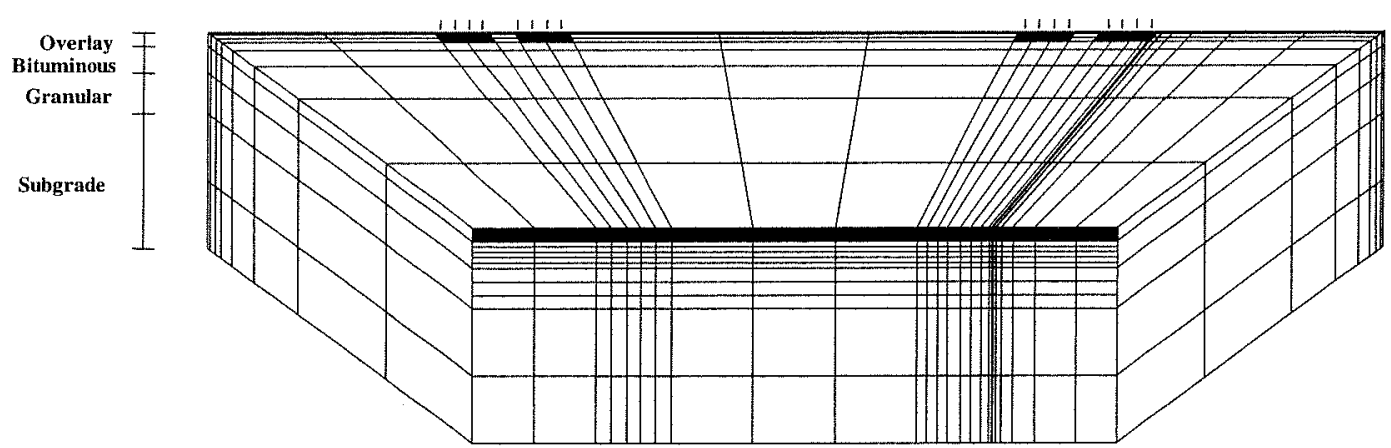

Figure 11. 3D finite element mesh used to calculate the crack activity after overlay.

\subsection{Estimated Crack Activity}

Finite elements were also used to develop a model to estimate the crack activity after overlay. The pavement was modeled as a 4 layers pavement, based on the mesh used to model the crack activity before overlay as shown in Figure 11.

Using the $3 \mathrm{D}$ finite element model, the vertical crack activity after overlay was calculated to fit in a statistical model and the Equation 2 was obtained.

$$
\text { Vertical activity after overlay }\left(10^{-6} \mathrm{~m}\right)=a *[\text { Overlay thickness }(\mathrm{m})]^{\mathrm{b}}
$$

Where:

$$
\begin{aligned}
& a=\prod_{i=1}^{6}\left[a_{1 i} * \ln \left(X_{i}\right)+a_{2 i}\right] \\
& b=\prod_{i=1}^{6}\left[b_{1 i} * \ln \left(X_{i}\right)+b_{2 i}\right]
\end{aligned}
$$

and $a_{\mathrm{ij}}$ and $b_{\mathrm{ij}}$ coefficients are given by the Table 3 .

This statistical model was developed based on crack activity after overlay representing the situation of an overlayed pavement. The application of this model give the crack activity that is applied to an overlay during its life. The crack activity after overlay measured in pavement was made changing the pavement near the crack, i.e. producing a hole in the overlay layer until the existing pavement. That hole reduces the overlay stiffness near the crack and thus the crack activity after overlay will be decreased. So, the crack activity after overlay measured in pavement cannot be compared with the one predicted with finite element results, which was calculated for a pavement without that hole. 
Table 3. Statistical coefficients for vertical crack activity after overlay model, $R^{2}=0.98$.

\begin{tabular}{|c|c|c|c|c|c|}
\hline$i$ & $X_{i}$ & $a_{1 i}$ & $a_{2 i}$ & $b_{1 i}$ & $b_{2 i}$ \\
\hline 1 & Cracked thickness (m) & $-2.487 \mathrm{E}-02$ & $-3.542 \mathrm{E}-01$ & $4.590 \mathrm{E}-03$ & $3.790 \mathrm{E}-01$ \\
\hline 2 & Granular thickness (m) & $1.448 \mathrm{E}-02$ & $-3.244 E-01$ & $8.765 \mathrm{E}-03$ & $-1.167 E+00$ \\
\hline 3 & Overlay modulus (MPa) & $3.441 \mathrm{E}-01$ & $1.952 \mathrm{E}+00$ & $5.794 \mathrm{E}-02$ & $1.173 E+00$ \\
\hline 4 & Cracked modulus (MPa) & $-2.640 \mathrm{E}-01$ & $8.469 \mathrm{E}+00$ & $9.997 \mathrm{E}-02$ & $7.102 \mathrm{E}-01$ \\
\hline 5 & Granular modulus (MPa) & $3.025 \mathrm{E}-01$ & $3.328 \mathrm{E}+00$ & $-8.531 \mathrm{E}-02$ & $1.287 E+00$ \\
\hline 6 & Subgrade modulus (MPa) & $-2.284 \mathrm{E}-01$ & $5.208 \mathrm{E}+00$ & $-7.745 \mathrm{E}-03$ & $8.043 E-01$ \\
\hline
\end{tabular}

The crack activity after overlay was compared with results of a finite elements model where an hole was defined to represent the situation produced for that measurements. That comparison shows that the crack activity after overlay measured in pavement can be predicted, with a sufficient accurate, by a numerical analysis.

\section{CONCLUSIONS}

To evaluate the reflective cracking potential of flexible pavement overlays, the crack activity under wheel loads must be measured. The crack activity before overlay can be measured using a CAM device or with two sensors of a FWD device. In this paper both devices were used.

The measurements with the FWD are very easy but only allow measuring the crack activity in one direction. In this case the vertical activity should be considered once the one that have more magnitude after overlay.

In this work, the crack activity of longitudinal and transverse cracks was measured but no expressive differences were found between these two types of cracks.

The analysis of the results of vertical and horizontal crack activity before overlay shows that some differences can be found during the winter and summer months.

The statistical models based on finite element results, both for pavement with and without overlay, follows the values measured in pavement with good accurate.

\section{ACKNOWLEDGEMENT}

The authors acknowledge and are thankful for the support provided by the National Road Administration for the facilities for crack activity measurements.

\section{REFERENCES}

Pais, J.C. 1999. Reflective Cracking in Flexible Pavement Overlay Design (in Portuguese). Ph.D. Thesis, University of Minho, Portugal.

Pais, Jorge C., Sousa, Jorge B., George B. Way \& Stubstad, Richard N. 2000. "An Overlay Design Method for Reflective Cracking", Asphalt Rubber 2000 Conference, Vilamoura.

Pais, Jorge C. \& Pereira, Paulo A.A. 2000. "Prediction of Existing Reflective Cracking Potential of Flexible Pavements", Fourth International RILEM Conference and Exhibition on Reflective Cracking in Pavements, Ottawa.

Rust, F.C. 1987. Load associated crack movement and aspects of the rehabilitation of reflection cracking in cemented pavements. University of Pretoria, South Africa. 